\title{
A FURANODITERPENOID FROM THE LIVERWORT JAMESONIELLA AUTUMNALIS*
}

\section{Hiroyuki Tazakl $†$ Martin Blechschmidt, $\ddagger$ Volker Huch,§ Michael Veith§ and HaNs Becker $\ddagger \|$}

łInstitut für Pharmakognosie und Analytische Phytochemie and §̧Institut für Anorganische Chemie, Universität des Saarlandes, D-66041 Saarbrüken, Germany

(Received 13 December 1993)

Key Word Index-Jamesoniella autumnalis; Hepaticae; furanoditerpenoid; jamesoniellide C; X-ray analysis.

Abstract-A new furanoditerpenoid, jamesoniellide $\mathrm{C}$, has been isolated from the liverwort Jamesoniella autumnalis. The structure of jamesoniellide $C$ was established by spectroscopic methods, including $\mathrm{X}$-ray analysis which also established its relative stereochemistry.

\section{INTRODUCTION}

Liverworts are known to be a rich source of sesquiterpenoids and diterpenoids, some of which are new structural types [1-3]. In the course of our investigation of these compounds [4-7], we have examined Jamesoniella autumnalis (DC) Steph. This species is distributed over the northern hemisphere in Europe, Asia, and America [8]. We have previously reported the isolation and structure elucidation of six ent-labdanes, and three furanoditerpenoids related to the clerodane type, i.e. jamesoniellides $A$ and $B$ and 17-acetoxy-18,12-dihydroxy-15,16-epoxy-cis-

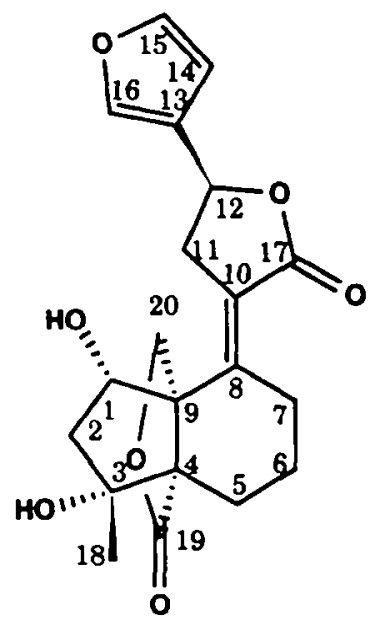

1

\footnotetext{
*Publication no. 76 of 'Arbeitskreis Chemie und Biologie der Moose.

tOn leave from Department of Bioresource Chemistry, Obihiro University of Agriculture and Veterinary Medicine. Inadacho, Obihiro 080, Japan.

$\|$ Author to whom correspondence should be addressed.
}

ent-cleroda-3,13(16),14-triene-22,18-olide, from J. autumnalis [9]. In this paper, we describe the structure of the newly isolated diterpenoid jamesoniellide $C$ (1) with a novel carbon skeleton.

\section{RESULTS AND DISCUSSION}

The extraction and fractionation of the liverwort $J$. autumnalis $(1100 \mathrm{~g}$, fr. wt) were described in a previous report [9]. Fraction 8 from the crude extract was further separated by several chromatographic steps to afford jamesoniellide $\mathbf{C}(1,15 \mathrm{mg}$ ). Jamesoniellide $\mathbf{C}(1)$, crystals (mp 199-201 ${ }^{\circ}$ ), showed a molecular ion peak in the HRCI mass spectrum at $m / z 375.1431$, corresponding to the molecular composition of $\mathrm{C}_{20} \mathrm{H}_{22} \mathrm{O}_{7}$. Further peaks at $m / z 357[M+1-18]^{+}$and $339[M+1-18-18]^{+}$, revealed the presence of two hydroxy groups. This was confirmed by the IR spectrum $\left(3470 \mathrm{~cm}^{-1}\right)$. The ${ }^{13} \mathrm{C}$ NMR spectrum showed the signals of one methyl, six methylenes, five methine and eight quaternary carbons, suggesting the presence of three double bonds. The IR $\left(875,1020,1505 \mathrm{~cm}^{-1}\right)$ and ${ }^{1} \mathrm{H}$ NMR $(\delta 6.39,7.40$ and 7.47) spectra suggested the presence of a $\beta$-substituted furan ring. The ester signal at $1740 \mathrm{~cm}^{-1}$ was overlapped by a carbonyl absorption at $1760 \mathrm{~cm}^{-1}$ which, in combination with the signals at $\delta 170.0$ and 178.3 in the ${ }^{13} \mathrm{C} N M R$ spectrum, indicated two lactones. The low field shift of the olefinic carbon at $\delta 160.8$ and the IR (band at $1635 \mathrm{~cm}^{-1}$ ) suggested one of the double bonds was conjugated with a carbonyl function. Therefore, the oxygens in the molecule corresponded to those in one furan ring, two hydroxy groups and two lactone rings. These facts mean jamesoniellide $C(1)$ is a pentacyclic diterpenoid.

${ }^{1} \mathrm{H}-{ }^{1} \mathrm{H}$ COSY and ${ }^{13} \mathrm{C}-{ }^{1} \mathrm{H}$ COSY experiments established the partial structures A-E except for the presence of two quaternary carbons (Fig. 1). The signals at $\delta 2.94$ 


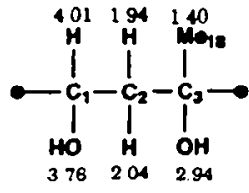

$\mathbf{A}$

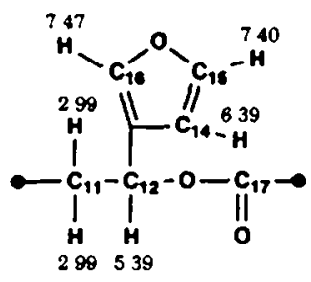

C

$$
c_{0}=c_{10}
$$

$\mathbf{E}$

- denotes a quaternary carbon

Fig. 1. Partial structures of jamesoniellide C (1)

and 3.76 in structure $\mathbf{A}$ were identified as hydroxy groups by exchange with $\mathrm{D}_{2} \mathrm{O}$. The long range coupling between $\mathrm{H}-16(\delta 7.47)$ and $\mathrm{H}-12(\delta 5.39)$ led to the structure $\mathrm{C}$.

${ }^{13} \mathrm{C}-{ }^{1} \mathrm{H}$ long range $\mathrm{COSY}$ and NOE experiments revealed some connections of each partial structure. The quaternary carbon $C-4(\delta 63.7)$ showed correlations with $\mathrm{Me}$ at $\mathrm{C}-3(\delta 1.40), \mathrm{H}-1(\delta 4.01)$ and $\mathrm{H}-6(\delta 1.06$ and 1.81$)$, and $\mathrm{C}-9(\delta 59.2)$ showed correlations with $\mathrm{H}-1, \mathrm{H}-20$ $(\delta 4.15$ and 5.09$)$, and $\mathrm{H}-5(\delta 1.16$ and 2.28$)$ which correlated with the signal at $\delta 170.0$. These results and the NOE observed from $\mathrm{H}-18$ to $\mathrm{H}-5$ led to structure $\mathrm{F}$ which combined the structures $A, B$ and $D$ with two quaternary carbons.

Furthermore, C-8 $(\delta 160.8)$ showed correlations with $\mathrm{H}-1, \mathrm{H}-6 . \mathrm{H}-11(\delta 2.99)$, and $\mathrm{H}-20(\delta 4.15$ and 5.09$)$, and $\mathrm{C}$ $10(\delta 122.2)$ showed correlations with $H-11, H-12$ and $H-$ $7 \alpha(\delta 2.12)$. These results suggested two alternative structures of 1 combining the structures $C, E$ and $F$ (Fig. 2). However, even though the IR spectrum $\left(1740,1760 \mathrm{~cm}^{-1}\right)$ and low-field shift of $\mathrm{C}-8$ in the ${ }^{13} \mathrm{CNMR}$ spectrum suggested the presence of an $\alpha_{1}, \beta$-unsaturated $\gamma$-lactone group, the structure of 1 could not be finally resolved by additional NOE experiments (Tables 1 and 2).

The structure elucidation of $I$ was completed by X-ray crystallographic analysis, which established the relative arrangement of the various partial structures and the stereochemistry (Fig. 3).
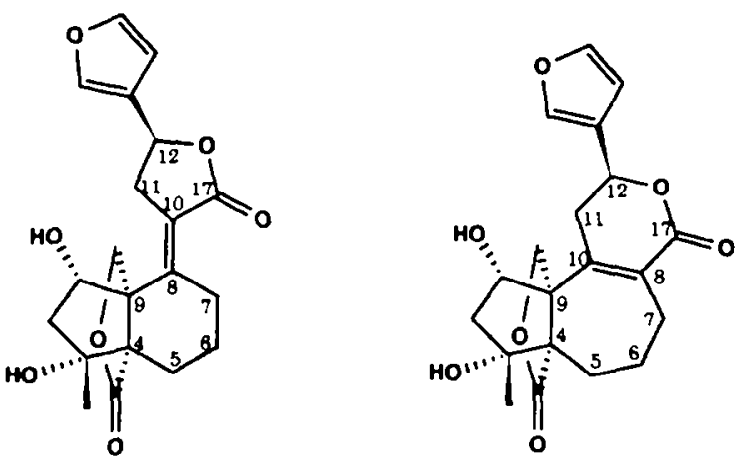

Fig. 2. Two alternative structures of jamesoniellide $C$ (1).

Table 1. ${ }^{1} \mathrm{H}$ and ${ }^{13} \mathrm{CNMR}$ spectral data of $1(400 \mathrm{MHz}$, $\left(\mathrm{CDCl}_{3}\right)^{*}$

\begin{tabular}{|c|c|c|c|}
\hline $\mathrm{C}$ & & $\mathbf{H}$ & \\
\hline 1 & 81.7 & 1 & $4.01 d d, J=5.8,11.5$ \\
\hline 2 & 47.2 & $\begin{array}{l}2 \alpha \\
2 \beta\end{array}$ & $\begin{array}{l}1.94 d . J=14.1 \\
2.04^{\circ} d d, J=1.9,6.1\end{array}$ \\
\hline 3 & 85.7 & & \\
\hline 4 & 63.7 & & \\
\hline \multirow[t]{2}{*}{5} & 28.8 & $5 x$ & $1.16^{\mathrm{b}} \mathrm{m}$ \\
\hline & & $5 \beta$ & $2.28 \mathrm{~m}$ \\
\hline \multirow[t]{2}{*}{6} & 19.7 & $6 x$ & $1.06^{\circ} \mathrm{m}$ \\
\hline & & $6 \beta$ & $1.81 \mathrm{~m}$ \\
\hline \multirow[t]{2}{*}{7} & 27.7 & $7 x$ & $2.12^{2} \mathrm{~m}$ \\
\hline & & $7 \beta$ & $3.85 \mathrm{br} d d, J=1.5,19.1$ \\
\hline 8 & 160.8 & & \\
\hline 9 & 59.2 & & \\
\hline 10 & 122.2 & & \\
\hline \multirow[t]{2}{*}{11} & 35.7 & $11 x$ & $2.99^{\circ} \mathrm{m}$ \\
\hline & & $11 \beta$ & $2.99^{\circ} \mathrm{m}$ \\
\hline \multirow[t]{2}{*}{12} & 71.1 & 12 & $5.39 t, J=6.8$ \\
\hline & 124.7 & & \\
\hline \multirow{2}{*}{$\begin{array}{l}14 \\
15\end{array}$} & 108.3 & 14 & $6.39 \mathrm{~m}$ \\
\hline & 144.1 & 15 & $7.40 \mathrm{~m}$ \\
\hline \multirow[t]{2}{*}{16} & 139.8 & 16 & $7.47 m$ \\
\hline & 170.0 & & \\
\hline \multirow[t]{2}{*}{8} & 21.2 & 18 & $1.40 \mathrm{~s}$ \\
\hline & 178.3 & & \\
\hline 20 & 73.6 & 20,20 & $4.15 d, 5.09 d, J=9.4$ \\
\hline & & $1-, 3-\mathrm{OH}$ & $3.76,2.94$ \\
\hline
\end{tabular}

*All assignments were accomplished by ${ }^{1} \mathrm{H}-{ }^{1} \mathrm{H}$ COSY, NOE, ${ }^{13} \mathrm{C}-{ }^{1} \mathrm{H}$ COSY and long range ${ }^{13} \mathrm{C}-{ }^{1} \mathrm{H}$ COSY experiments

- 'Signals partly overlapping.

Recently, Nagashima et al. [10] have reported that the terpenoids from $J$. autumnalis collected in Japan are based on four ent-kaurane type diterpenoid structures. From a chemotaxonomic point of view, there must be at least two different chemical races of $J$. autumnalis, one producing 1, labdane and clerodane type diterpenoids, the other producing ent-kaurane type diterpenoids.

\section{EXPERIMENTAL}

HPLC was carried out as previously reported [9]. Optical rotations: $\mathrm{CHCl}_{3}$; $\mathrm{NMR}:{ }^{1} \mathrm{H}$ at $400 \mathrm{MHz},{ }^{13} \mathrm{C}$ at 


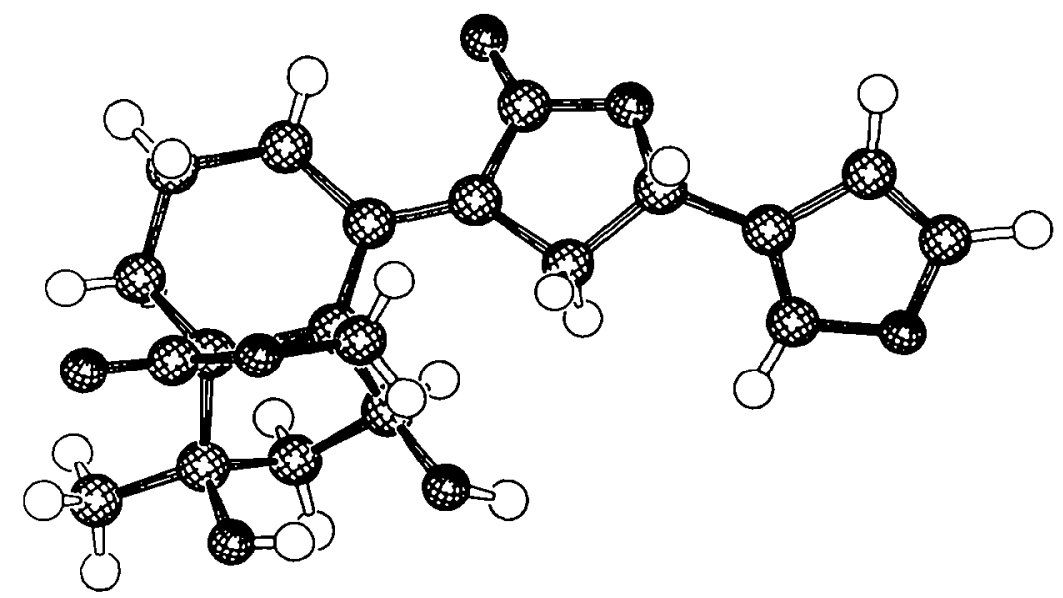

Fig. 3. SCHAKAL drawing of the molecule of jamesoniellide $\mathrm{C}$ (1) with the atomic numbering.

Table 2. NOE experiment on 1

\begin{tabular}{ll}
\hline $\begin{array}{l}\text { Irradiation } \\
H\end{array}$ & $\begin{array}{l}\text { Observed NOE } \\
\text { (signal enhancements per œnt) }\end{array}$ \\
\hline 1 & H-11 (5.7), H-14 (1.2), H-16 (1.9) \\
$2 \beta$ & $\mathrm{H}-18(1.4)$ \\
18 & $\mathrm{H}-5 x(2.3), \mathrm{H}-5 \beta(2.1)$ \\
20 & $\mathrm{H}-11(4.9)$ \\
20 & $\mathrm{OH}-1(8.6), \mathrm{H}-11(3.9)$ \\
\hline
\end{tabular}

$100.5 \mathrm{MHz}_{2} \mathrm{CDCl}_{3}$, relative to $\mathrm{CHCl}_{3}$ at $\delta_{\mathrm{H}} 7.25$ and $\mathrm{CDCl}_{3}$ at $\delta_{\mathrm{CH}} 77.0$, respectively. ${ }^{13} \mathrm{C}$ multiplicities were determined using the DEPT pulse sequence.

Jamesoniella autumnalis (DC) Steph. was collected in December 1988 near Orscholz Saar and identified by Prof. Mues. Voucher specimens were deposited at the Institute of Pharmakognosie und Analytische Phytochemie der Universität des Saarlandes, Saarbrücken.

Extraction and isolation of 1 . Previously, 8 frs were obtained from the crude extract $(10.24 \mathrm{~g})$ of the ground

Table 3. Crystallographic data and data collection characteristics for the X-ray analysis of 1

\begin{tabular}{|c|c|}
\hline \multicolumn{2}{|l|}{ Crystal data } \\
\hline Molecular formula & $\mathrm{C}_{20} \mathrm{H}_{22} \mathrm{O}$, \\
\hline$M,\left(\mathrm{~g} \mathrm{~mol}^{-1}\right)$ & 374.4 \\
\hline Crystal system & Monoclinic \\
\hline Space group & $\mathbf{P} \mathbf{2}_{1}$ \\
\hline Cell dimensions $(\boldsymbol{A}) a$ & $7.135(7)$ \\
\hline$b$ & $12.566(10)$ \\
\hline$c$ & $10.357(9)$ \\
\hline$\beta$ & $104.79(7)$ \\
\hline Volume $\left(\AA^{-3}\right)$ & $897.9(14)$ \\
\hline$Z$ & 2 \\
\hline Density $\left(8 \mathrm{~cm}^{-3}\right)$ & 1.385 \\
\hline Absorption coefficient $\left(\mathrm{cm}^{-1}\right)$ & 1.05 \\
\hline$F(000)$ & 396 \\
\hline \multicolumn{2}{|c|}{ Data collection: Siemens Stoe AED2 } \\
\hline \multicolumn{2}{|c|}{$\begin{array}{l}\text { Graphite monochromated MoK } \alpha ; \omega / \theta \text { scans; scan width } 1.20^{\circ}+\mathrm{K} \alpha \text {-separation; scan } \\
\text { speed } 4.0 \text { to } 1.1^{\circ} \min ^{-1} ; 2 \theta \text { range } 3 \text { to } 50^{\circ} ;\end{array}$} \\
\hline Reflections collected & 3340 \\
\hline Independent reflections & $3166\left(R_{i n t}=0.88 \%\right)$ \\
\hline Observed reflections & $2679(F>2.0 \curvearrowleft(F))$ \\
\hline$R$-value & 0.062 \\
\hline \multicolumn{2}{|c|}{ Computer and programs usod: Siemens SHELXTL PLUS (VMS [11]) } \\
\hline
\end{tabular}


material (1100 g, fr. wt) by vacuum liquid chromatography on silica gel ( $n$-hexane-EtOAc, gradient) [9]. Chromatography [Sephadex $\mathrm{LH}-20$ with $\mathrm{CH}_{2} \mathrm{Cl}_{2}-\mathrm{MeOH}$ $(1: 1)$ as an eluant, silica gel with $n$-hexane-EtOAc $(3: 2)$ as an eluant, and HPLC with a Diol column and nhexane-EtOAc $(3: 2)$ as an eluant] of fr. $8(100 \%$ EtOAc) afforded 1 ( $15 \mathrm{mg}$ crystallization from EtOAc and $\mathrm{MeOH}$ ). Mp 199-201\% [ $\alpha]_{D}-54.1^{*}(c 0.015)$. HRMS $\mathrm{C}_{20} \mathrm{H}_{23} \mathrm{O}$, Found: $m / z 375.1431[\mathrm{M}+1]^{+}$, requires 375.1444 . IR $v^{\mathrm{KBr}}$ $\mathrm{cm}^{-1}: 3470,1760,1740,1635,1505,1170,1020,875 ;{ }^{1} \mathrm{H}$ and ${ }^{13}$ C NMR: Table 1; CIMS m/z (rel. int.): $375[\mathrm{M}+1]^{+},(12)$, 357 (42), 338 (26), 295 (6), 289 (100), 271 (22), 243 (17), 201 (8), $167(5), 149$ (15), 87 (100).

$X-R a y$ structure determination of 1 . Experimental details of the X-ray diffraction analysis of 1 are listed in Table 3. The data were corrected for Lorentz and polarization effects. but not for absorption. The structure was refined first isotropically, then anisotropically. The hydrogen atoms were located in difference maps and they were included in the last cycles of the refinement and refined. The highest peak in the final difference Fourier had a density less than $0.25 \mathrm{e}^{-3}$.

The relative configuration of 1 was determined by a micro-Vax with the following programs: SHELX [11], SCHAKAL [12]

Lists of atomic coordinates, thermal parameters, structure factors, bond lengths, bond angles and torsion angles of 1 are deposited at the Cambridge Crystallographic Data Centre.

Acknowledgement-We thank Dr Zapp, Institut für Pharmakognosie und Analytische Phytochemie, Universität des Saarlandes, for running NMR spectra. H.T. is indebted to the Ministry of Education, Science and Culture in Japan for a research fellowship.

\section{REFERENCES}

1. Huneck, S. (1983) in New Manual of Bryology (Schuster, R. M., ed.), Vol. 1, p. 1. Hattori Botanical Laboratory, Nichinan, Japan.

2. Asakawa, Y. (1982) in Prog. in the Chemistry of Organic Natural Products (Herz, W., Grisebach, H. and Kirby, E. W., eds), Vol. 42, p. 1. Springer, Wien.

3. Zinsmeister, H. D., Becker, H. and Eicher, T. (1991) Angew Chem., Int. Ed. Engl. 30, 130.

4. Beyer, J., Becker, H., Toyota, M. and Asakawa, Y. (1987) Phytochemistry 26, 1085.

5. Morais, R. M. S. C. Harrison, L. J. and Becker, H. (1988) J. Chem. Res. Synop. 380.

6. Spörle, J., Becker, H., Gupta, M. P., Veith, M. and Huch, V. (1989) Tetrahedron 16. 5003.

7. Nabeta, K., Mototani, Y., Tazaki, H. and Okuyama, H. (1994) Phytochemistry 35, 915.

8. Schuster, R. M. (1983) New Manual of Bryology Vol. 1, (Schuster, R. M., ed.), p. 463. The Hattori Botanical Laboratory, Japan.

9. Blechschmidt, M. and Becker, H. (1992) J. Nat. Prod. 55, 111.

10. Nagashima, F., Toyota, M. and Asakawa, Y. (1990) Phytochemistry 29, 2169.

11. Sheldrick, G. M. (1993) Program for Crystal Structure Determination, version 1993

12. Keller, E. (1992) Schakal 92, Program for Crystal Structure Determination, version 1992, Crystallograph. Institut., Univ. of Freiburg, Germany. 